\title{
LOCALIZED BASAL FREEZING WITHIN GEORGE VI ICE SHELF, ANTARCTICA
}

\author{
By M. Pedley,* J.G. PARen, and J.R. Potter ${ }^{\dagger}$ \\ (British Antarctic Survey, Natural Environment Research Council, High Cross, \\ Madingley Road, Cambridge CB3 OET, England)
}

\begin{abstract}
Hobbs Pool is an area of thin ice shelf situated within George VI Ice Shelf, Antarctica. Thicker ice shelf surrounding Hobbs Pool isolates the upper $155 \mathrm{~m}$ of the water column from water lying at the same depth elsewhere under the ice shelf. Summer melt-water lakes drain through crevasses at Hobbs Pool forming a $155 \mathrm{~m}$ thick layer of low-salinity water close to its freezing point. Colder and more saline water in the lower part of this layer leads to in-situ freezing of fresher water lying above it. Below $155 \mathrm{~m}$ depth, the water temperature and salinity are linearly related by basal melting which is observed elsewhere under the ice shelf. The surface ice shows areas of deformation and deposits of subglacial rock debris which may result from upward particle paths in the area. The raising of subglacial rock debris on to the ice surface may provide a mechanism for the transport of erratics across the ice shelf to Alexander Island from the base of Palmer Land glaciers.
\end{abstract}

George VI Ice Shelf lies in George VI Sound between the Antarctic Peninsula and Alexander Island (see Fig. 1). The ice shelf is $100 \mathrm{~m}$ thick at the northern ice front and thickens steadily with increasing latitude to reach a maximum of $500 \mathrm{~m}$ east of the Eklund Islands group. The ice then thins to $200 \mathrm{~m}$ at the southern ice front (Crabtree, 1983). The ice flow is dominated by Palmer Land glaciers, and the flow lines of glaciers draining from the Antarctic Peninsula can be traced across the ice shelf to where they abut the Alexander Island coastline. Flow is disturbed by Alexander Island glaciers only along the extreme western edge of the ice shelf. Hobbs Pool is adjacent to the coastal mountains of Palmer Land and lies $180 \mathrm{~km}$ to the south of the northern ice front. The flow pattern of the glaciers entering the ice shelf in the vicinity of Hobbs Pool has left an area of thin ice between the steep rocky coast and the main body of the ice shelf. The earliest studies of the water column under the ice shelf in this area were made by drilling through a small section of lake ice at the landward edge of the thin-ice area, to which the name Hobbs Pool was originally applied (Bishop and Walton, 1981). This has now disappeared and this paper extends the name to include the surrounding area of disturbed ice shelf. The boundaries of Hobbs Pool cannot be precisely defined but, in recent years, measurements have been made over an area of several square miles in the vicinity of lat. $71^{\circ} 17^{\prime} \mathrm{S}$., long. $67^{\circ} 35^{\prime} \mathrm{W}$., where crevassing in the ice shelf allows access to the water column. The water deepens extremely rapidly away from the coastline and depths of over $600 \mathrm{~m}$ have been measured only $1 \mathrm{~km}$ from the coast.

During the summer, George VI Ice Shelf undergoes extensive ablation. The consequences of this are most

\footnotetext{
*Present address: Marconi Maritime Applied Research Laboratory, Milton Road, Cambridge CB4 4FX, England.

†Present address: Saclant Centre, 19026 San Bartolomeo, La Spezia, Italy.
}

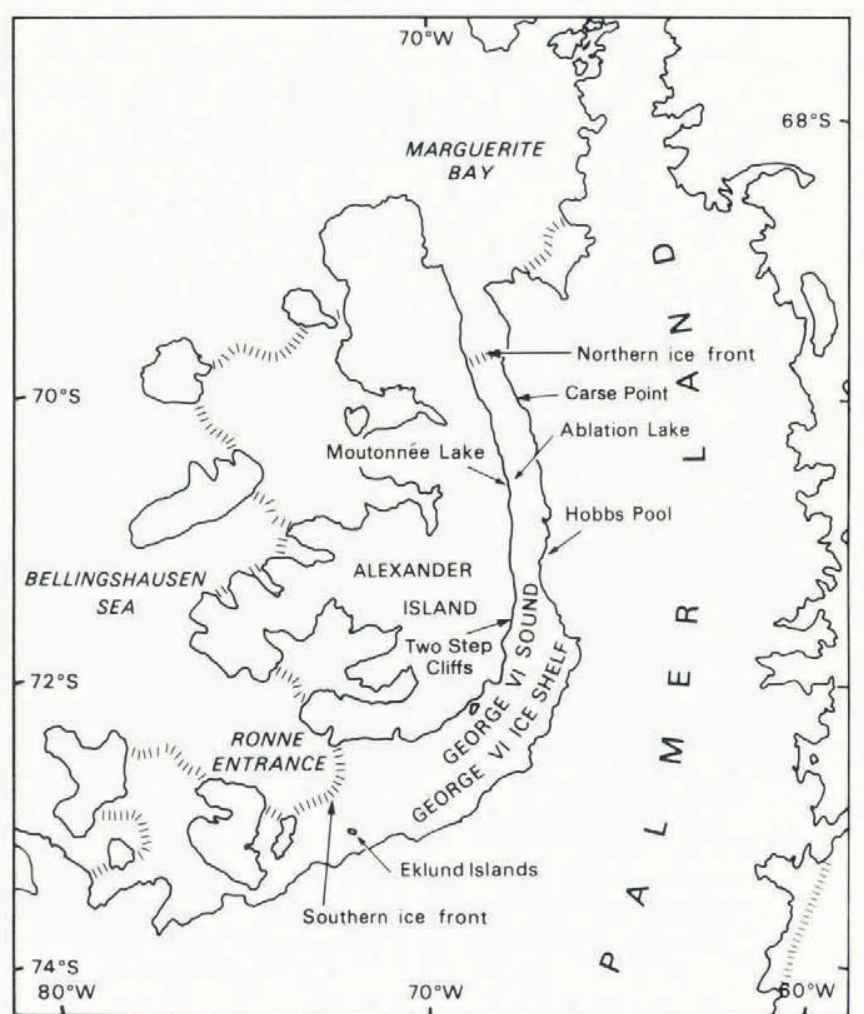

Fig. 1. Map of the Antarctic Peninsula and George VI Ice Shelf.

apparent in the central area of the ice shelf, from lat. $70^{\circ} 15^{\prime}$ to $72^{\circ} 00^{\prime} \mathrm{S}$., where surface melt-water lakes regularly form. Figure 2 shows a satellite image taken in February 1985 showing the lakes in this section of the ice shelf. The formation and distribution of the lakes has been discussed by Reynolds (1981). The compression resulting from Palmer Land glaciers entering the ice shelf inhibits the formation of crevasses which could drain the melt water. Instead, melt water descends through the upper firn and accumulates on an impermeable ice layer formed from the freezing of the previous summer's melt water. With continued ablation, the level can rise enough to form freshwater lakes at the surface. The break in the ice shelf at Hobbs Pool provides a localized drainage route for the surrounding lakes, and streams flowing into the area are a common feature during the summer. Input from surface streams draining off the Palmer Land coast appears to be minimal. Towards the end of February, the surface lakes start to freeze over and drainage into Hobbs Pool declines for the winter. 


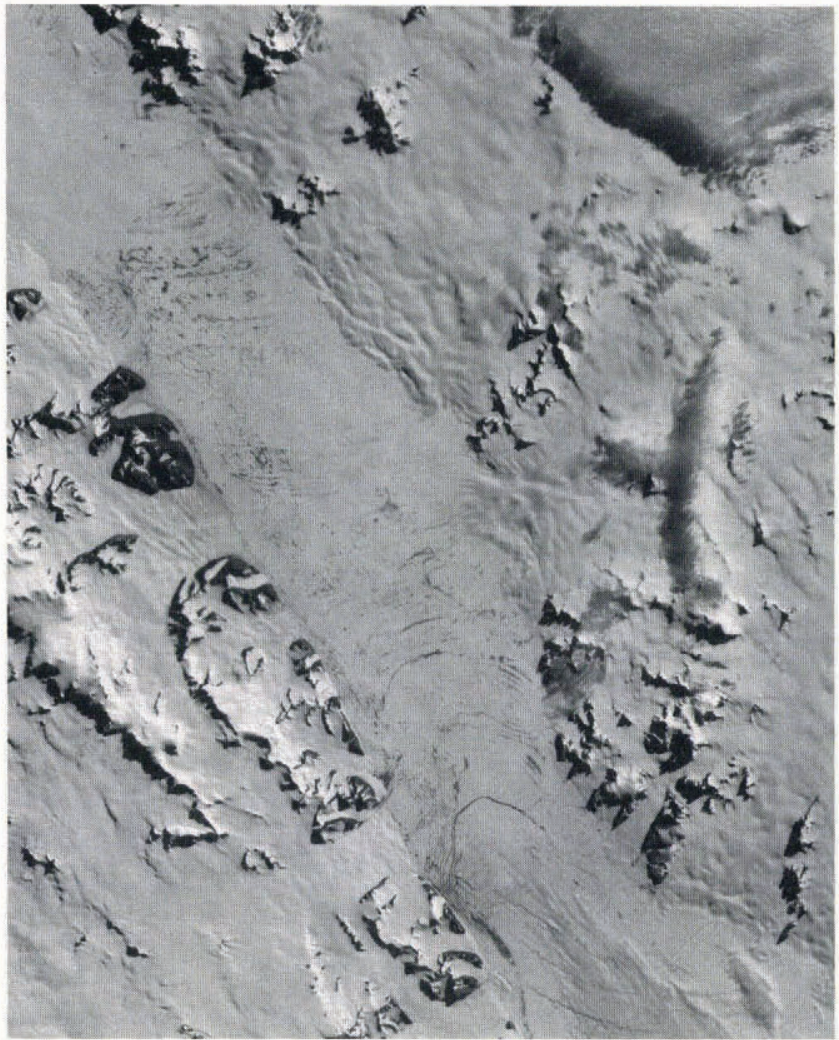

Fig. 2. A satellite image taken in February 1985 showing extensive melt-water lakes in the central area of George VI Ice Shelf. Surface measurements have shown that the melt-water lakes are aligned along ice-flow lines. (Landsat, path 217, row 110, No. 50362-12360-4, 26 February 1985.)

The earliest measurements at Hobbs Pool were made in 1974 using mercury reversing thermometers in conjunction with water-sampling bottles (Bishop and Walton, 1981). Approximate values of salinity were obtained on site using a simple conductivity cell. In early 1983, a profiling temperature/conductivity probe provided the first continuous measurements to the sea floor. In the 1983-84 and 1984-85 austral summers, further measurements were taken with mercury reversing thermometers and water-sampling bottles. The salinities of the samples were later measured on a laboratory salinometer, with the exception of some very low-salinity samples down to $65 \mathrm{~m}$ depth, whose salinity was inferred from chlorinity measurements. The chlorinities of the samples from 1983-84 were determined using a Dionex $2010 \mathrm{i}$ ion chromatograph and those from 1984-85 by titration. Simultaneous measurements on a salinometer confirmed that the standard relation between chlorinity and salinity was applicable.

\section{THE WATER CHARACTERISTICS}

The salinity and temperature of the water column are plotted in Figure 3 and the discrete measurements are listed in Table I. The extremely low salinity of the upper $72 \mathrm{~m}$ results from the inflow of melt water at the surface during the austral summer but not until about $155 \mathrm{~m}$ depth do the salinities approach values typical of the world's seas. The halocline at $72 \mathrm{~m}$ is remarkably sharp and separates almost fresh water from that with salinity of approximately $25 \%$. The halocline is associated with a sharp temperature drop which continues to $155 \mathrm{~m}$ depth. Below $155 \mathrm{~m}$, the temperature increases steadily to the sea floor with a smaller thermocline at $177 \mathrm{~m}$ depth. The interval between the earliest and latest temperature measurements is 11 years, and the water column appears to have remained virtually unchanged throughout this period.

The vertical temperature and salinity gradients have been calculated from the continuous profiling data, and the almost discontinuous behaviour can be seen in Figure 4 . Persistent gradients of this magnitude are extremely unusual and their strength makes measurements difficult. Mercury reversing thermometers measure the temperature in the region of the bulb, while the water sample collected is, at best, an average over the length of the bottle. In fact, incomplete flushing of the sampling bottle during its descent means that the sample collected is influenced by the water through which the bottle has recently passed, resulting in a further displacement between the depths of simultaneous temperature and salinity measurements. The conductivity and temperature sensors on the continuously profiling probe were closely spaced, which reduces this problem. The effect of the thermal inertia in the temperature sensor is to increase the effective transducer separation, and was reduced by slowing the motion of the instrument through the thermoclines and by using comparisons of upward and downward profiles. The plots in Figure 4 are the result of running a differentiating filter through a smooth spline fit to the digitized data. This smoothing means that the gradients in Figure 4 are, if anything, underestimates.

The different regimes in the water column can be distinguished by plotting temperature directly against salinity in a $T-S$ diagram (Fig. 5). Scatter between the discrete measurements reaches a maximum near $72 \mathrm{~m}$, which is to be expected from the extreme gradients at this level. The continuous profiles also showed considerable scatter at this depth, due both to the thermal inertia of the probe's temperature sensor and to errors inherent in digitizing rapidly changing temperature-depth and salinity-depth profiles. The continuous profile in Figure 5 is drawn as a dashed line where its accuracy is suspect. The diagram divides into two sections, with the transition between them occurring at the $155 \mathrm{~m}$ deep temperature minimum. The water above $155 \mathrm{~m}$ depth is of low salinity owing to the input of fresh water at the surface, while the water at greater depths reflects the main sub-ice-shelf circulation.

\section{THE DEEP LAYER (155 $\mathrm{m}$ TO THE SEA FLOOR)}

Measurements taken at the northern ice front of George VI Ice Shelf have shown that a linear $T-S$ relationship extends from the surface to the sea floor (Lennon and others, 1982). In Figure 6, the data from Hobbs Pool for depths below $155 \mathrm{~m}$ are plotted alongside data from six sites along the northern ice front and from one site adjacent to Carse Point (lat. $70^{\circ} 15^{\prime} \mathrm{S}$., long. $68^{\circ} 12^{\prime} \mathrm{W}$.). At Carse Point, the ice shelf terminates in an ice cliff overlooking a small polynya but, unlike Hobbs Pool, the area is not affected by melt-water lakes; saline water extends from the surface downwards. The close agreement between data from the different sites indicates that the processes determining the water structure below $155 \mathrm{~m}$ depth at Hobbs Pool are those occurring at all depths in an area extending south from the northern ice front at least to the latitude of Carse Point. The linear $T-S$ diagram at the northern ice front has been interpreted (Potter and Paren, 1985) as a product of the basal melting of the ice shelf into Circumpolar Deep Water which is advected at depth under the ice shelf. The observed gradient of $2.41 \pm 0.09$ deg $\mathrm{ppt}^{-1}$ change in salinity closely confirms the prediction of $2.50 \pm 0.05 \mathrm{deg} \mathrm{ppt}^{-1}$ salinity change from a model for this process (Potter and Paren, 1985) based on Gade (1979). It is likely that $155 \mathrm{~m}$ represents the depth at which there is an unconstrained route for water communication with the northern ice front and Marguerite Bay beyond. Radio-echo data indicate a typical ice-shelf thickness of $200 \mathrm{~m}$ surrounding Hobbs Pool and an ice thickness decreasing steadily to the northern ice front (Crabtree, 1983). If communication at $155 \mathrm{~m}$ depth is possible, then the maximum ice thickness on the minimum depth route to the northern ice front can be calculated knowing the mean iceshelf density and integrating the density profile in the seawater. With a mean ice-shelf density of $908 \mathrm{~kg} \mathrm{~m}^{-3}$, reported by Bishop and Walton (1981) near Hobbs Pool, an ice depth of $155 \mathrm{~m}$ below sea-level corresponds to an ice thickness of $172 \mathrm{~m}$. This is somewhat less than indicated by radio-echo data but may simply correspond to a subglacial channel along the Palmer Land margin of the ice shelf. At the northern ice front the main thermocline occurs at the base of the ice shelf. If this is also the case at Hobbs Pool, the 

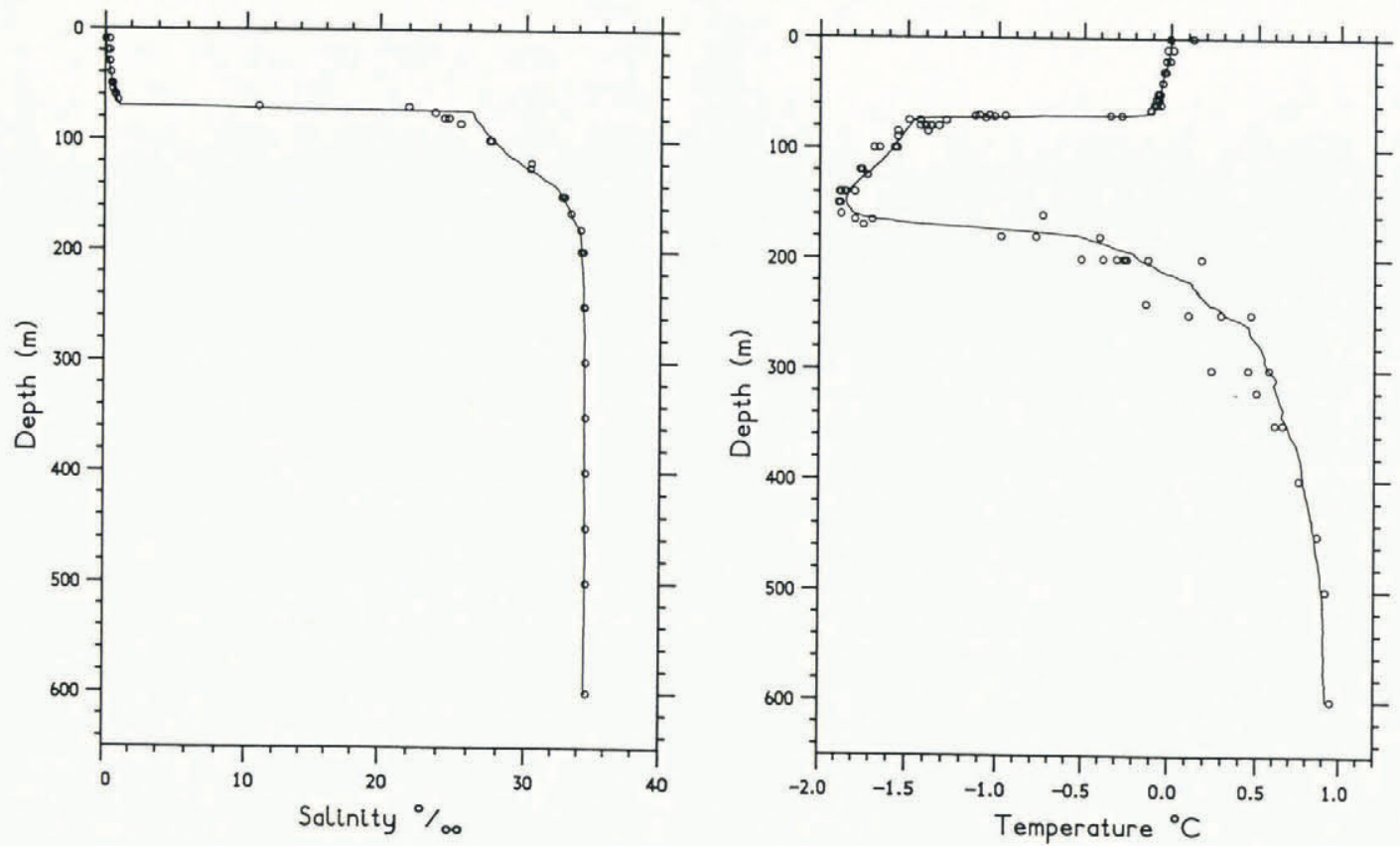

Fig. 3. The salinity and temperature profiles at Hobbs Pool. The continuous lines are data from the profiling temperature-conductivity probe, while the discrete points are from water-sampling bottles and reversing thermometers.

Salinity gradient

Temperature gradient
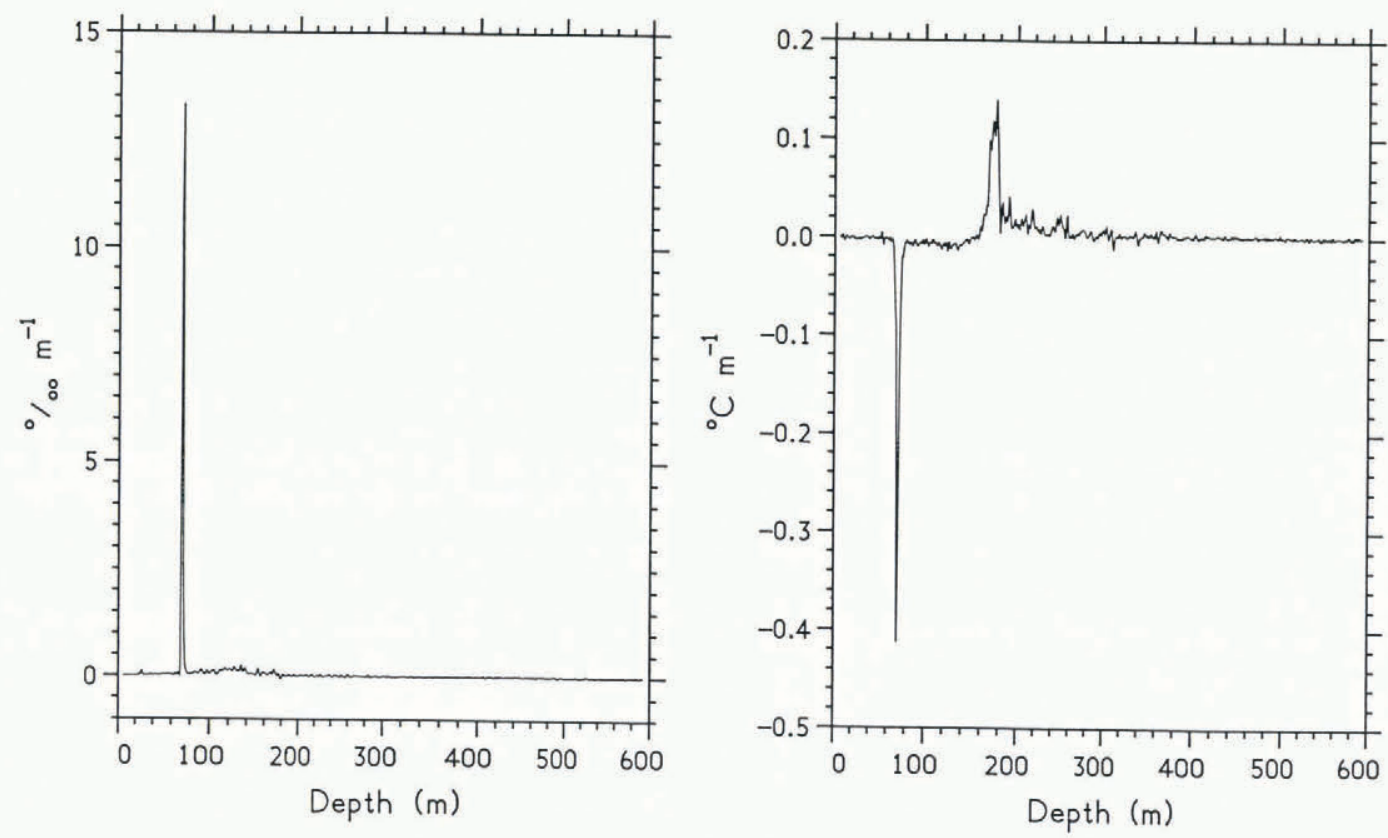

Fig. 4. The gradients of the continuous temperature and salinity profiles.

thermocline at $177 \mathrm{~m}$ depth (Fig. 4) indicates the depth of the main shelf in the area. Equivalent to an ice thickness of $197 \mathrm{~m}$, this agrees with the BAS 500R ice-thickness map of Alexander Island (Crabtree, 1983) which marks a $200 \mathrm{~m}$ ice-thickness contour on the ice shelf adjacent to Hobbs Pool.

\section{THE UPPER LAYER (SURFACE TO $155 \mathrm{~m}$ )}

The existence and stability of the halocline at $72 \mathrm{~m}$ can be explained by proposing an appropriate geometry for the surrounding ice shelf. The mouth of Disraeli Fiord in northern Ellesmere Island has a similar water structure to that found at Hobbs Pool (Keys, 1978). Disraeli Fiord is dammed by the Ward Hunt Ice Shelf and the upper $44 \mathrm{~m}$ of the water column in the fjord comprises fresh water. The depth of the halocline corresponds to the typical draught of the ice shelf in this area and continuing freshwater input at the surface simply depresses the saline layer to the base of the ice shelf, allowing an outflow of the more buoyant fresh water into the Arctic Ocean. At Hobbs Pool the situation is somewhat different as the minimum 
TABLE I. TEMPERATURE (T), SALINITY $(S)$, TEMPERATURE ABOVE THE IN-SITU FREEZING POINT $\left(T_{\mathrm{f}}\right)$, AND DENSITY AT HOBBS POOL FROM THE DISCRETE MEASUREMENTS. THE DATA NEAR THE $72 \mathrm{~m}$ DEEP BOUNDARY ARE UNRELIABLE. FREEZING POINTS ARE CALCULATED AFTER FUJINO AND OTHERS (1974)

$\begin{array}{ccccc}\underset{\mathrm{m}}{\text { Depth }} & { }^{\circ} \mathrm{C} & T-T_{\mathrm{f}} & \mathscr{\phi}_{0} & \sigma_{\mathrm{t}}\end{array}$

1983-84 austral summer

$\begin{array}{rrrrr}10 & 0.02 & 0.03 & 0.07 & -0.10 \\ 20 & 0.00 & 0.03 & 0.21 & 0.02 \\ 30 & -0.02 & 0.02 & 0.41 & 0.18 \\ 40 & -0.04 & 0.01 & 0.50 & 0.25 \\ 50 & -0.06 & 0.02 & 0.65 & 0.37 \\ 60 & -0.08 & 0.02 & 0.91 & 0.58 \\ 65 & -0.11 & 0.00 & 1.04 & 0.69 \\ 70 & -1.11 & 0.14 & 22.01 & 17.64 \\ 80 & -1.33 & 0.07 & 24.69 & 19.81 \\ 85 & -1.39 & 0.06 & 25.48 & 20.44 \\ 100 & -1.57 & 0.01 & 27.56 & 22.13 \\ 120 & -1.75 & 0.01 & 30.45 & 24.48 \\ 150 & -1.89 & 0.03 & 33.00 & 26.55 \\ 150 & -1.88 & 0.04 & 32.91 & 26.48 \\ 165 & -1.79 & 0.17 & 33.46 & 26.93 \\ 180 & -0.40 & 1.61 & 34.19 & 27.47 \\ 200 & 0.18 & 2.22 & 34.42 & 27.63 \\ 250 & 0.47 & 2.55 & 34.52 & 27.70\end{array}$

1984-85 austral summer

$\begin{array}{rrrrr}10 & -0.02 & 0.01 & 0.40 & 0.17 \\ 20 & -0.02 & 0.02 & 0.42 & 0.19 \\ 30 & -0.04 & 0.01 & 0.42 & 0.18 \\ 50 & -0.06 & 0.01 & 0.54 & 0.28 \\ 55 & -0.06 & 0.01 & 0.64 & 0.36 \\ 60 & -0.05 & 0.03 & 0.78 & 0.48 \\ 70 & -0.27 & 0.37 & 10.90 & 8.67 \\ 75 & -1.29 & 0.06 & 23.79 & 19.07 \\ 80 & -1.38 & 0.01 & 24.41 & 19.58 \\ 100 & -1.55 & 0.01 & 27.43 & 22.03 \\ 125 & -1.72 & 0.03 & 30.38 & 24.42 \\ 150 & -1.87 & 0.03 & 32.76 & 26.36 \\ 200 & -0.30 & 1.73 & 34.23 & 27.50 \\ 250 & 0.29 & 2.37 & 34.47 & 27.66 \\ 300 & 0.57 & 2.70 & 34.57 & 27.73 \\ 350 & 0.66 & 2.82 & 34.61 & 27.75 \\ 400 & 0.76 & 2.96 & 34.63 & 27.77 \\ 450 & 0.87 & 3.11 & 34.66 & 27.78 \\ 500 & 0.92 & 3.19 & 34.67 & 27.78 \\ 600 & 0.95 & 3.30 & 34.72 & 27.82\end{array}$

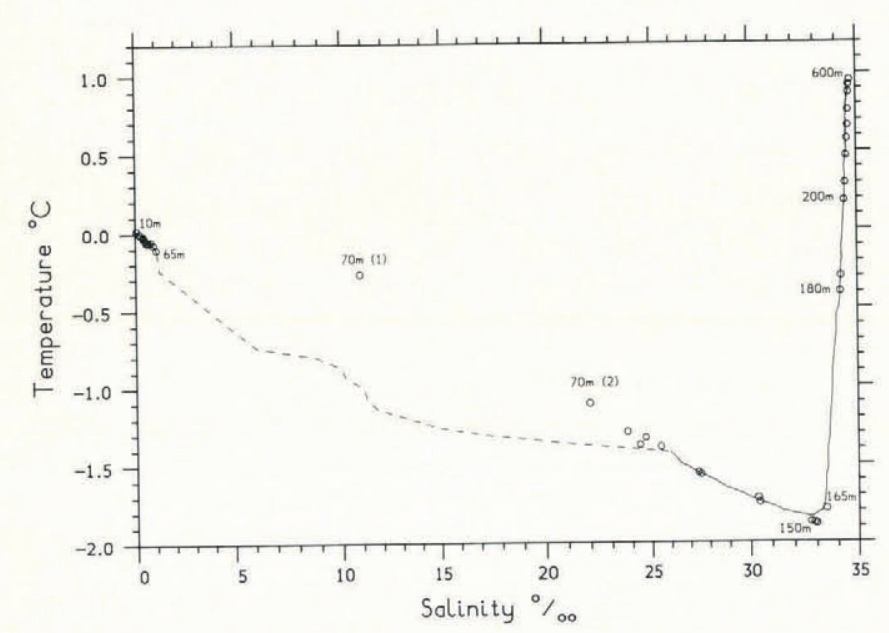

Fig. 5. The $T-S$ (temperature-salinity) diagram at Hobbs Pool. The data are shown dashed in the depth range where they are unreliable. The discrete measurements are listed in Table $I$.

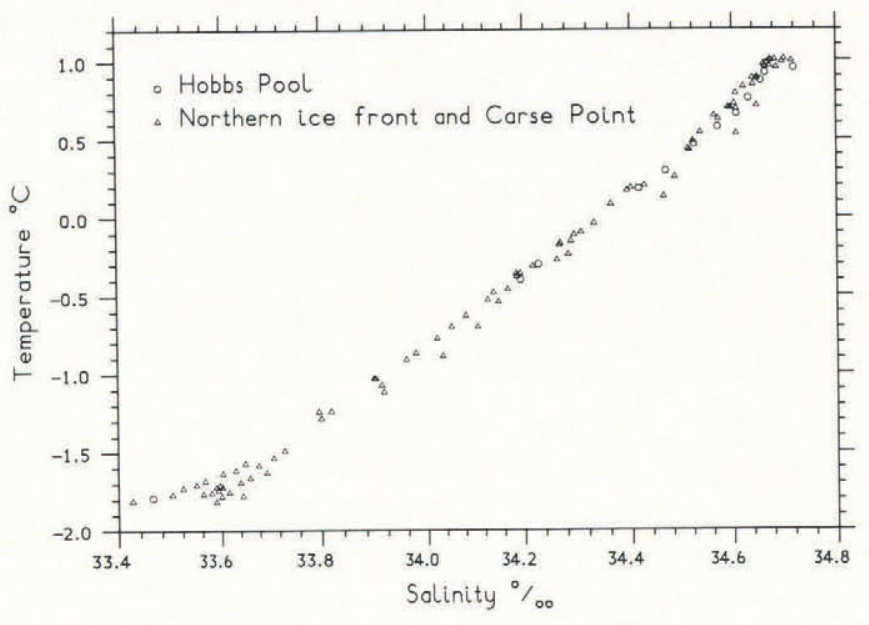

Fig. 6. The expansion of the high-salinity section of Figure 5 , with data superimposed from sites along the northern ice front and from beside Carse Point.

depth for outflow under the main ice shelf is $155 \mathrm{~m}$, as discussed in the previous section. Rather than corresponding to a depth at which there can be totally unconstrained horizontal motion of the water, the $72 \mathrm{~m}$ deep halocline at Hobbs Pool probably results from a substantial increase in its cross-sectional area. Within this simple model of the ice morphology, it is possible to show that freezing can occur in Hobbs Pool and to calculate the freezing rate. The calculations for summer and winter must be performed separately due to seasonal differences in the dominating physical processes.

During the austral summer the melt-water input into Hobbs Pool depresses the deeper saline layer until an outflow of buoyant fresh water into a relatively unconstrained area occurs at a depth of $72 \mathrm{~m}$. This has the effect of maintaining a severe pycnocline at this depth. The continuous $T-S$ profile is plotted alongside the in-situ calculated freezing curve in Figure 7 . With the exception of the continuously profiled data between 69 and $73 \mathrm{~m}$ depth, which as mentioned earlier are unreliable, the upper water column from the surface to near $155 \mathrm{~m}$ depth is close to the in-situ freezing point. The difference between the in-situ temperature from the discrete water-bottle and temperature measurements and the calculated freezing point is also listed in Table I; in no case is supercooling observed. Martin and Kauffman (1974) noted a potential cause of mixing at interfaces like the pycnocline at $72 \mathrm{~m}$. They showed that, as a result of supercooling, a density inversion can occur immediately above a pycnocline caused by fresh water at its freezing point overlying colder salty

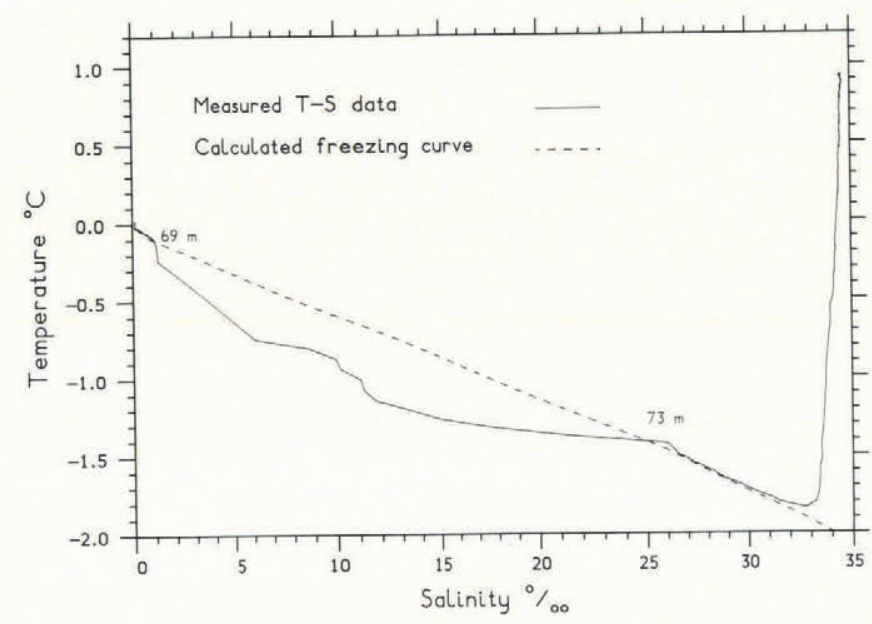

Fig. 7. The continuous $T-S$ diagram for Hobbs Pool together with the calculated in-situ freezing curve. 
water. This then leads to a convective-transport mechanism several times more efficient than molecular diffusion. Such a process is unlikely at Hobbs Pool; the low salinity above the interface is sufficient to inhibit the density inversion and, furthermore, there is no evidence of supercooling. In principle, double diffusion is possible in the upper $72 \mathrm{~m}$ because the very low salinity means an increase in temperature and results in an increase in density. However, the temperature gradient is very small and the column remains stable. As the weak tidal currents expected under the main shelf are not capable of causing turbulent mixing at an interface about $80 \mathrm{~m}$ above the main tidal stream, molecular diffusion is taken to be the sole active transport process. If the advective process maintaining the pycnocline is in equilibrium with the diffusive process degrading it, the freezing point at a given depth will remain constant with respect to time. In the absence of supercooling, the heat diffusing across the thermocline must be in balance with latent heat released above $72 \mathrm{~m}$ depth by the formation of frazil ice, which will drift up the water column without melting and accumulate at the base of the ice above. The rate of production of frazil ice can be found by calculating the rate of heat diffusion across the thermocline, the severity of which is assumed constant as for the halocline. If $r$ and $L$ are the rate of formation and the specific latent heat of fusion of ice, and $\mathrm{k}_{\mathrm{T}}, T$, and $C$ are the thermal diffusivity, temperature, and specific heat capacity of water, then

$$
\rho=-\frac{\mathbf{k}_{\mathrm{T}} C \rho}{L} \frac{\partial T}{\partial z}
$$

where the temperature gradient is measured at $z_{0}$, the depth of the centre of the thermocline. Using a value for the gradient of $-0.41 \mathrm{deg} \mathrm{m}^{-1}$ (see Fig. 4), Equation (1) gives a freezing rate of $6.6 \times 10^{-7} \mathrm{~kg} \mathrm{~m}^{-2} \mathrm{~s}^{-1}$ or $1.2 \times 10^{-2} \mathrm{~m}$ of ice per square metre of thermocline over the 6 month summer period. Values chosen for the thermocline were: $\mathrm{k}_{\mathrm{T}}=1.3 \times$ $10^{-7} \mathrm{~m}^{2} \mathrm{~s}^{-1}, C=4.1 \mathrm{~kJ} \mathrm{~kg}^{-1}{ }^{\circ} \mathrm{C}^{-1}, \rho=1015 \mathrm{~kg} \mathrm{~m}^{-3}$, and $L=$ $334 \mathrm{~kJ} \mathrm{~kg}^{-1}$. The salt excluded by the formation of this volume of frazil ice has a negligible effect on the salinity, confirming that in this analysis the diffusion of salt may be considered independently of the diffusion of heat.

During the winter, the melt-water input into Hobbs Pool declines and the outflow at $72 \mathrm{~m}$ ceases. Diffusive processes continue, however, slowly degrading the pycnocline, the halocline being broadened at a rate determined by the coefficient of molecular diffusion for salt. At any point in the pycnocline, therefore, the rate of change of salinity is given by

$$
\frac{\partial S}{\partial t}=\kappa_{S} \frac{\partial^{2} S}{\partial z^{2}}
$$

where $\mathbf{k}_{\mathrm{s}}$ is the molecular diffusivity of salt and $S$ the salinity. The solution of Equation (2) that describes the development of a halocline which is initially a salinity step with amplitude $\Delta S$ and mean $\bar{S}$ is given by

$$
S(z, t)=\frac{1}{2} \Delta S \operatorname{erf}\left[\frac{z-z_{0}}{2\left(\mathrm{k}_{s} t\right)^{\frac{1}{2}}}\right]+\bar{S}
$$

where erf is the error function (see, for example, Carslaw and Jaeger, 1959). By time $t$, the halocline "width" has expanded to $4\left(\mathrm{k}_{\mathrm{s}} t\right)^{\frac{1}{2}}$ which, by the end of the winter (that is, $t=6$ months), is $0.5 \mathrm{~m}$. Again, in the absence of supercooling, heat diffusing from the water above $72 \mathrm{~m}$ that would otherwise reduce the temperature below the in-situ freezing point is balanced, as in the summer, by the latent heat of formation of frazil ice. It is easily shown that, more than about $0.3 \mathrm{~m}$ above the centre of the halocline, the depression of the freezing point due to upwards diffusion of salt over 6 months is insignificant. The development of the thermocline can therefore be approximated by assuming that the temperature above $72 \mathrm{~m}$ is constant throughout the 6 winter months. The temperature variation from $72 \mathrm{~m}$ downwards is given by

$$
T(z, t)=T+\Delta T\left[\frac{1}{2}-\operatorname{erf}\left[\frac{z-z_{0}}{2\left(\mathrm{k}_{\mathrm{T}} t\right)^{\frac{1}{2}}}\right]\right]
$$

where $\Delta T$ is the difference in the temperatures above and below the thermocline, and $\bar{T}$ their mean. The extent of the thermocline below $72 \mathrm{~m}$ is therefore $2\left(\mathrm{k}_{\mathrm{T}} t\right)^{\frac{1}{2}}$ which, for $t=$ 6 months, is $2.9 \mathrm{~m}$. Including the $0.3 \mathrm{~m}$ broadening above $72 \mathrm{~m}$, the total extent of the thermocline will be about $3.2 \mathrm{~m}$.

The graph in Figure 8 shows the results from the measurements made in August 1974 using sampling bottles and reversing thermometers (Bishop and Walton, 1981). The absolute values of the salinities, plotted here as in-situ freezing points, have been shown to be suspect, but the trend they demonstrate may be considered reliable. The graph shows the expected asymmetry in the temperature profile, and that the size of the thermocline is in broad agreement with the results of the diffusion model. However, the asymmetry in the freezing-point profile represents a clear divergence from the shape expected for a system in which salt is transported by a purely diffusive process. In fact, within the accuracy of the data, the freezing-point and temperature curves are superimposed. The salt-transport mechanism giving rise to a freezing-point profile so similar in shape to the temperature profile is not known. When the salinity in the lower part of the pycnocline drops below $25.0 \%$, double diffusion is in principle possible, although it should be inhibited by the strong salinity gradient. Such activity would, however, explain the observed profiles. Furthermore, if double diffusion were to occur, the result would be layering (rather than "fingering"), providing a possible explanation for the unrepeatability and scatter in measurements made in the lower part of the thermocline compared with those made in the upper part.

In the simple diffusion model, the volume of frazil ice produced during the winter months can be found by calculating the heat flow $H_{\text {total }}$ across the thermocline as follows:

$$
H_{\text {total }}=\int_{z=z_{0}}^{\infty} C \rho[T(z, t=6 \text { months })-T(z, t=0)] \mathrm{d} z . \text {. (5) }
$$

From Equations (4) and (5), $H_{\text {total }}=-C \rho \Delta T=6.4 \times 10^{6} \mathrm{~J}$, corresponding to $2.1 \times 10^{-2} \mathrm{~m}$ of frazil-ice formation per square metre of thermocline. By integrating the temperature-depth graph in Figure 8 over depths below the thermocline, and subtracting the area corresponding to heat gained from above it, a value for frazil-ice formation of $2.5 \times 10^{-2} \mathrm{~m} / \mathrm{m}^{2}$ is obtained, agreeing well with the theory.

In conclusion, to re-establish the thermocline during the summer, sufficient melt water to depress the interface by $3-4 \mathrm{~m}$ must flow into Hobbs Pool. About $1 \%$ of this necessary input will freeze as frazil ice and accumulate in a layer $2-3 \mathrm{~cm}$ thick at the base of the ice above the thermocline.

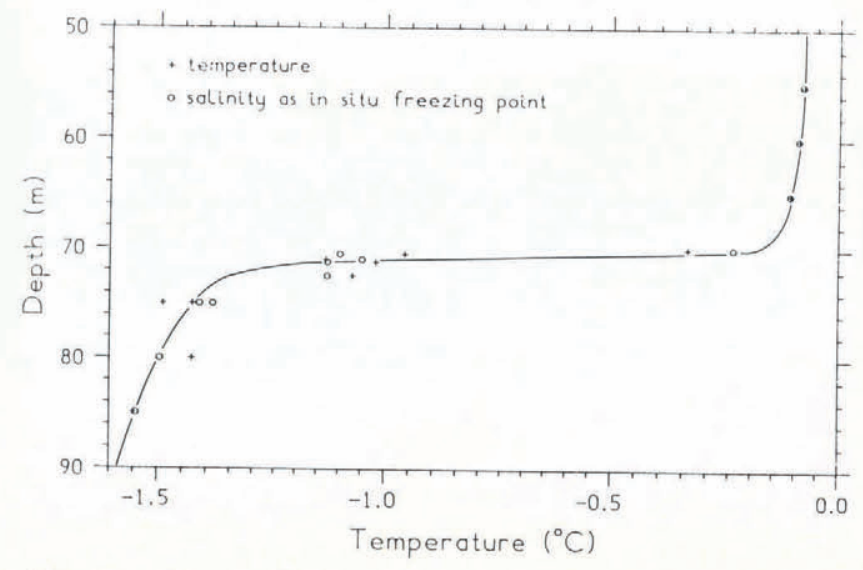

Fig. 8. The variation in temperature and freezing point with depth at Hobbs Pool in August 1974 (after Bishop and Walton, 1981). 


\section{THE EXTENT OF LOW-SALINITY WATER}

Drainage does not occur through the ice shelf away from the coastline (Reynolds, 1981). It is likely, however, that there exist additional areas along both coasts of George VI Ice Shelf lying within the latitude range affected by melt water where ice flow is disrupted by the coastal topography and where there exist drainage routes through the ice shelf. On the east coast of the ice shelf these will be areas similar to Hobbs Pool where the Palmer Land coastline can shield an area from local glacier flow. The ice shelf on the west coast is under compression which will prevent the formation of extensive areas of thin ice shelf. Areas of disrupted ice shelf may occur only at the edge of those Alexander Island valleys which are partially filled with ice tongues, as at Ablation and Moutonnee Lakes.

\section{SURFACE MORAINES AT HOBBS POOL}

In January 1985, morainic material was found ablating through the ice shelf at Hobbs Pool (Fig. 9). The rock debris was composed of scoured pebbles evidently from a subglacial source rather than from rockfalls rafted away from the coastline. The ice in the vicinity of the moraines had a domed appearance with an unusual criss-cross pattern of cracking indicating tension in two perpendicular directions, which was highly suggestive of upthrust from beneath. As the ice at Hobbs Pool is under tension, these features were not pressure ridges formed by compressive buckling. Moraines had not been seen at Hobbs Pool prior to the 1984-85 summer and have never been found on the main ice-shelf surface away from the coastlines.

The appearance of subglacial rock debris on the surface of an ice shelf requires the initial incorporation of the rock on to the ice shelf's base together with continued basal

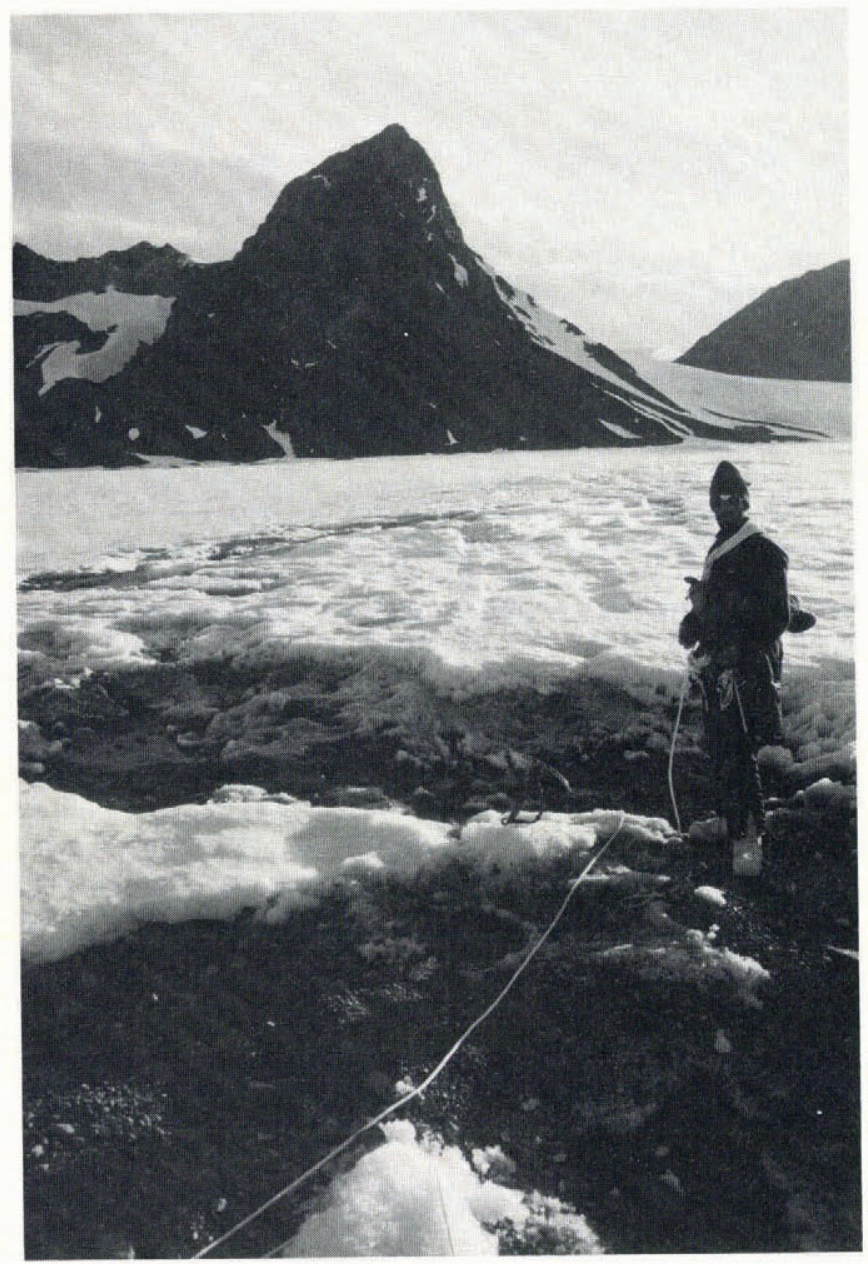

Fig. 9. A moraine ablating through the surface ice at Hobbs Pool with the Palmer Land coast in the background. freezing and net surface ablation. There is a small valley glacier to the south-east of the moraines and, as the ice flow is to the north-west, this is the most likely source of the rock debris. The rock debris could have been incorporated on to the glacier base while it was stil aground and then transported towards the area of basal freezing at Hobbs Pool where new ice may have been added beneath it. Snow-accumulation measurements on George VI Ice Shelf have been discussed by Bishop and Walton (1981). The central area of the ice shelf is in a severe precipitation shadow resulting from the mountains of Alexander Island but all measurements on the ice shelf show positive accumulation rates. Accumulation measurements in this area of the ice shelf are difficult to make because of the summer melt, but Bishop and Walton (1981) reported a low net accumulation rate of $0.10 \mathrm{~m} \mathrm{a}^{-1}$ ice for a site close to Hobbs Pool. Net accumulation over the ice shelf explains the absence of subglacial debris over most of the ice-shelf surface. However, net ablation is required for upward particle paths and for the appearance of moraines on the surface at Hobbs Pool. The ice shelf around the Hobbs Pool moraine is probably no more than $20 \mathrm{~m}$ thick, whereas it is $200 \mathrm{~m}$ thick further to the west. Moraines can therefore appear more rapidly on the ice-shelf surface at Hobbs Pool in response to a temporary run of a few years of low accumulation and high ablation than they can on the main ice-shelf surface. The general net accumulation over the ice shelf must prevent their surfacing elsewhere. The formation of melt-water lakes on the ice shelf is encouraged by the same factors (low accumulation and high ablation) that bring the moraines to the surface. Melt-water lakes were extensive during the 1984-85 austral summer.

\section{THE TRANSPORT OF PALMER LAND ROCK DEBRIS} ACROSS GEORGE VI SOUND

Sugden and Clapperton (1981) found moraines on the east coast of Alexander Island which were interpreted as having been deposited by the westward flow of George VI Ice Shelf. While comprised mainly of rock originating from the local area of Alexander Island, they concluded that subglacial debris from Palmer Land was also present. This could not be reconciled with the extensive evidence that melting dominates the processes occurring at the ice-shelf base. This would melt out any debris on the base of the ice shelf before it could cross George VI Sound. The existence of a localized area of basal freezing at Hobbs Pool, together with the probable existence of similar areas elsewhere on the Palmer Land coast, may provide a mechanism for the transport of subglacial rock debris from Palmer Land to Alexander Island. Glacier ice leaving Palmer Land containing embedded rock debris at its base will be subjected initially to basal freezing which will raise it higher into the ice shelf, followed by basal melting as it moves away from the coast. Bishop and Walton (1981) measured the variation of velocity and vertical strain-rate along two flow lines on George VI Ice Shelf. The "L scheme" flow line terminated near Ablation Point, while the "M scheme" ended at Two Step Cliffs. The steady-state particle paths along the flow lines can be calculated from these data after Crary and others (1962); the resulting paths are shown in Figure 10, where the data have been extrapolated to each grounding line. The model indicates that material which is initially less than $80 \mathrm{~m}$ deep on the Palmer Land coast can be carried right across George VI Sound to Ablation Point; for material being transported to Two Step Cliffs, the maximum initial depth is $70 \mathrm{~m}$. The distribution of Palmer Land erratics, which extend from Ablation Valley to Two Step Cliffs, provides indirect evidence that areas of basal freezing exist along the Palmer Land coastline in addition to Hobbs Pool if indeed the erratics were deposited in the same steady-state environment as postulated for today's model. Extensive moraine layers within an ice shelf can appear on radio-echo surveys as an extra reflecting layer within the ice sheet. Doake (1981) found such a layer near the Ellsworth Mountains where a moraine layer was identified off the Independence Hills. Radio-echo data from flights over the central area of George VI Ice Shelf do not show internal layering, indicating that if moraine layers do exist within George VI Ice Shelf they are too weak to have been detected. 

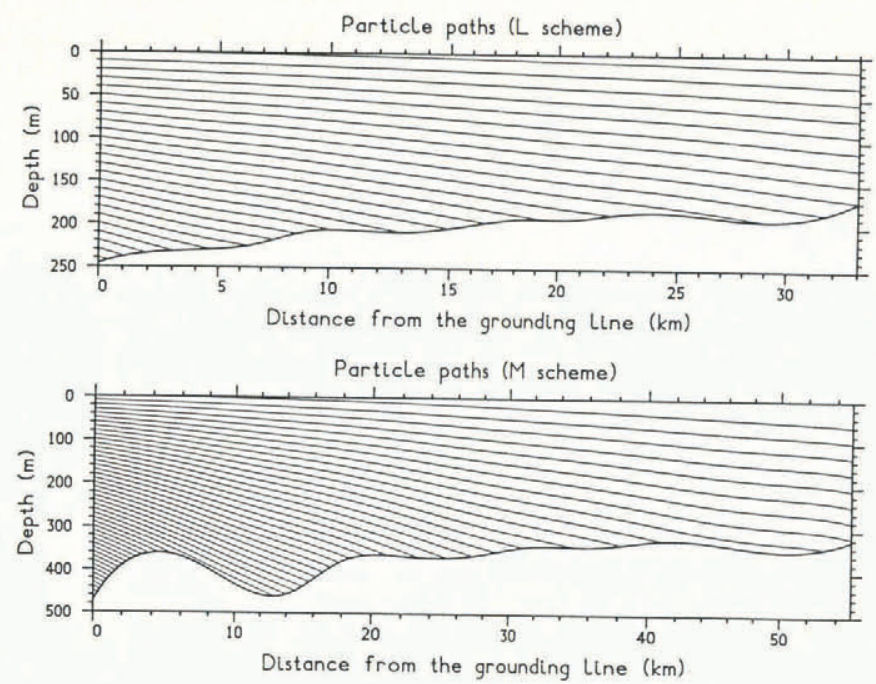

Fig. 10. Computed particle paths along two flow lines from Palmer Land to Alexander Island.

\section{SURFACE MORAINES ON MCMURDO ICE SHELF}

Extensive surface deposits of rock debris and faunal remains have been found on the surface of McMurdo Ice Shelf, Antarctica. The area experiences net ablation during the year with extensive melting occurring during the summer months. Cores taken through the ice shelf show it to be composed of fresh-water ice (Gow and others, 1965). Drainage of surface melt water leads to the existence of a fresh-water layer whose presence at the beginning of the ablation season indicates that it is a year-round feature (Gow and others, 1965). Debenham (1965) proposed that this layer was freezing on to the base of the ice shelf, leading to a situation similar to that at Hobbs Pool where the fresh-water ice formed at the base of the ice derives from melt water formed on its surface. This was confirmed by Gow (1967), who calculated a basal freezing rate of $0.5 \mathrm{~m} \mathrm{a}^{-1}$ on the Koettlitz Glacier tongue which forms the western edge of McMurdo Ice Shelf. Swithinbank (1970) discussed the mechanism by which the debris was first incorporated on to the ice-shelf base and concluded that the formation of anchor ice around sea-floor material was probably the dominant mechanism.

\section{CONCLUSION}

Drainage from melt-water lakes on George VI Ice Shelf leads to the existence of a localized area where the normal process of melting at the ice-shelf base is replaced by basal freezing. It is unlikely that basal freezing is restricted to Hobbs Pool. Its contribution to the mass balance of the ice shelf is unlikely to be significant but it may allow rock debris to be transported from the base of Palmer Land glaciers to the Alexander Island coast, although basal melting occurs along the greater part of the flow line.

\section{ACKNOWLEDGEMENTS}

The authors would like to thank R. Mulvaney, of the British Antarctic Survey, who analysed the majority of the water samples, and the support staff of the British Antarctic Survey, in particular, A.G.F. Collins, P.J. Cleary, and J. Tighe who worked with us in the field. F. Culkin, of the Institute of Oceanographic Sciences at Wormley, kindly determined the chlorinity of the very low-salinity water samples.

\section{REFERENCES}

Bishop, J.F., and Walton, J.L.W. 1981. Bottom melting under George VI Ice Shelf, Antarctica. Journal of Glaciology, 27(97), 429-47.

Carslaw, H.S., and Jaeger, J.C. 1959. Conduction of heat in solids. Second edition. Oxford, Oxford University Press.

Crabtree, R.D. 1983. British Antarctic Territory ice thickness map, 1:500 000. Sheet 1. Alexander Island. Cambridge, British Antarctic Survey.

Crary, A.P., Robinson, E.S., Bennett, H.F., and Boyd, W.W. 1962. Glaciological studies of the Ross Ice Shelf, Antarctica, 1957-1960. IGY Glaciological Report, 6.

Debenham, F. 1965. The genesis of the McMurdo Ice Shelf, Antarctica. Journal of Glaciology, 5(42), 829-32.

Doake, C.S.M. 1981. Tracing particle paths in the Antarctic ice sheet. Journal of Glaciology, 27(97), 483-86.

Fujino, K., Lewis, E.L., and Perkin, R.G. 1974. The freezing point of seawater at pressures up to 100 bars. Journal of Geophysical Research, 79(12), 1792-97.

Gade, H.G. 1979. Melting of ice in sea water: a primitive model with application to the Antarctic ice shelf and icebergs. Journal of Physical Oceanography, 9(1), 189-98.

Gow, A.J. 1967. Antarctic glaciological studies. Antarctic Journal of the United States, 2(4), 121-22.

Gow, A.J., Weeks, W.F., Hendrickson, G., and Rowlands, R. 1965. New light on the mode of uplift of the fish and fossiliferous moraines of the McMurdo Ice Shelf, Antarctica. Journal of Glaciology, 5(42), 813-28.

Keys, J.E. 1978. Water regime of Disraeli Fiord. Ellesmere Island. Ottawa, Defence Research Establishment. (Report No. 792.)

Lennon, P.W., Loynes, J., Paren, J.G., and Potter, J.R. 1982. Oceanographic observations from George VI Ice Shelf, Antarctic Peninsula. Annals of Glaciology, 3, 178-83.

Martin, S., and Kauffman, P. 1974. The evolution of under-ice melt ponds, or double diffusion at the freezing point. Journal of Fluid Mechanics, 64(3), 507-27.

Potter, J.R., and Paren, J.G. 1985. Interaction between ice shelf and ocean in George VI Sound, Antarctica. In Jacobs, S.S., ed. Oceanology of the Antarctic continental shelf. Washington, DC, American Geophysical Union, 35-58. (Antarctic Research Series 43.)

Reynolds, J.M. 1981. Lakes on George VI Ice Shelf, Antarctica. Polar Record, 20(128), 425-32.

Sugden, D.E., and Clapperton, C.M. 1981. An ice-shelf moraine, George VI Sound, Antarctica. Annals of Glaciology, 2, 135-41.

Swithinbank, C. 1970 . Ice movement in the McMurdo Sound area of Antarctica. International Association of Scientific Hydrology Publication 86 (ISAGE), 472-87. 